\begin{tabular}{|c|c|c|}
\hline 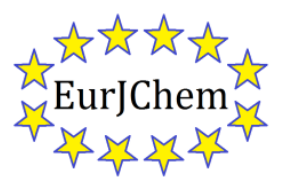 & $\begin{array}{c}\text { European Journal of Chemistry } \\
\text { Journal homepage: } \underline{w w w . e u r j c h e m . c o m ~}\end{array}$ & 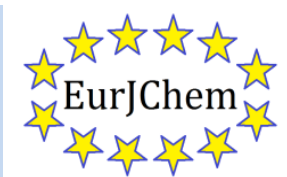 \\
\hline
\end{tabular}

\title{
Synthesis, characterization and crystal structure of 1-(4-methylbenzoyl)-3-(4 aminosulfonylphenyl)thiourea
}

\author{
Aamer Saeeda, ${ }^{a}$ Amara Mumtaz a and Ulrich Flörke ${ }^{\mathrm{b}}$ \\ a Department of Chemistry, Quaid-I-Azam University, Islamabad, 45320, Pakistan \\ b Department Chemie, Fakultät fur Naturwissenschaften, Universitat Paderborn, Warburgerstrasse 100, D-33098, Paderborn, Germany \\ *Corresponding author at: Department of Chemistry, Quaid-I-Azam University, Islamabad, 45320, Pakistan. Tel.: +92.51.90642128; fax: +92.51.90642241. \\ E-mail address: aamersaeed@yahoo.com (A. Saeed).
}

\section{ARTICLE INFORMATION}

\section{Received: 4 April 2010}

Received in revised form: 9 April 2010

Accepted: 9 April 2010

Online: 30 June 2010

\section{KEYWORDS}

Thiourea

Sulfonyl thiourea

Single crystal X-ray diffraction

\section{ABSTRACT}

An efficient synthesis of the title compound, 1-(4-methylbenzoyl)-3-(4-aminosulfonyl phenyl)thiourea, was carried out by reaction of 4-methylbenzoyl chloride with potassium thiocyanate in acetone to afford 4-methylbenzoyl isothiocyanate in situ followed by treatment with sulfanilamide. The structure was confirmed by spectroscopic data and elemental analyses. The molecular structure was determined from single crystal X-ray diffraction data. It crystallizes in the monoclinic space group P $2_{1} / \mathrm{n}$ with unit cell dimensions of $a=4.8116(9) \AA$, $b=17.150(3) \AA, c=18.677(3) \AA, \gamma=96.487(4)^{\circ}$, and $V=1531.4(5) \AA^{3}$.

\section{Introduction}

1,3-disubstitued thioureas are extremely versatile building blocks for the synthesis of a variety of heterocyclic compounds and exhibit a wide spectrum of bioactivities. $N, N$-Dialkyl $-N$ aroyl thioureas are efficient ligands for the separation of platinum group metals [1]. 1,3-Dialkyl or diaryl thioureas exhibit significant antifungal activity against plant pathogens Pyricularia oryzae and Drechslera oryzae [2]. 1-Benzoyl-3-(4,6disubstituted-pyrimidin-2-yl)thioureas display excellent herbicidal activity [3]. Acyl thioureas are well known for their superior pesticidal, fungicidal, antiviral and plant growth regulating activities [4]. 1-Aroyl-3-arylthioureas have recently been used in the synthesis of imidazole-2-thiones and imino thiazolines $[5,6]$.

Sulfanilamide and its derivatives are still widely used in chemotherapy effectively against a broad range of microorganisms [7-8]. These are true anti-metabolites; they block a specific step in the biosynthetic pathway of folic acid [9]. More than 12000 sulfonyl thiourea derivatives are known and some of them are very potent hypoglycemic agents due to their ability to stimulate the release of insulin from the pancreatic islets. Examples of the first generation sulfonylureas include carbutamide, the first sulfonylurea used as an effective oral hypoglycemic agent which is more effective than IPTD, tolbutamide, chlorpropamide, tolazamide and those as the second generation are glyburide and glipizide. The present work aimed at appending the sulfanilamide moiety to thiourea nucleus in order to combine their beneficial effects in a single structure with expected bioactivities including anticancer activity.

The title compound, 1-(4-methylbenzoyl)-3-(4-amino sulfonylphenyl)thiourea, belong to a unique class of thioureas in which the free aniline nitrogen is incorporated into the thiourea structure compared to all other known urea derivatives which involve the sulfonamide amino group as part of the thiourea moiety.

\section{Experimental}

\subsection{Instrumentation}

Melting points were recorded using a digital Gallenkamp (SANYO) model MPD.BM 3.5 apparatus and are uncorrected. ${ }^{1} \mathrm{H}$ and ${ }^{13} \mathrm{C}$ NMR spectra were determined as chloroform-d solutions using a Bruker AM-300 spectrophotometer. FTIR spectra were recorded on an FTS $3000 \mathrm{MX}$ spectrophotometer. Mass spectra was acquired (EI, $70 \mathrm{eV}$ ) on a MAT 312 instrument, and elemental analyses were conducted using a LECO-183 CHNS analyzer. Crystallographic data were collected on a Bruker-AXS SMART APEX CCD diffractometer. The crystal structure was solved by direct methods. H-atoms were located from difference Fourier maps and then refined at idealized positions with riding model. Details on data collection and refinement are given in Table 1.

\subsection{Synthesis}

A solution of 4-methylbenzoyl chloride $(10 \mathrm{mmol})$ in acetone $(50 \mathrm{~mL})$ was added dropwise to a suspension of potassium thiocyanate $(10 \mathrm{mmol})$ in acetone $(30 \mathrm{~mL})$ and the reaction mixture was refluxed for $30 \mathrm{~min}$. After cooling to room temperature, a solution of sulfanilamide $(10 \mathrm{mmol})$ in acetone $(10 \mathrm{~mL})$ was added and the resulting mixture was refluxed for $3 \mathrm{~h}$ (Scheme 1). The reaction mixture was poured into cold water and the precipitated thiourea was recrystallized using aqueous methanol. Yield $=(1.33 \mathrm{~g}, 64 \%) . \mathrm{R}_{\mathrm{f}}=0.7$; M.p.: 209210ㄷ. IR ( $\mathrm{cm}^{-1}$ ): 1590 (arom. C=C), $1663(\mathrm{C}=0), 3317(\mathrm{~N}-\mathrm{H})$, $1263(\mathrm{C}=\mathrm{S}), 1158(\mathrm{C}-\mathrm{N}), 1334(\mathrm{~S}=0)$. 


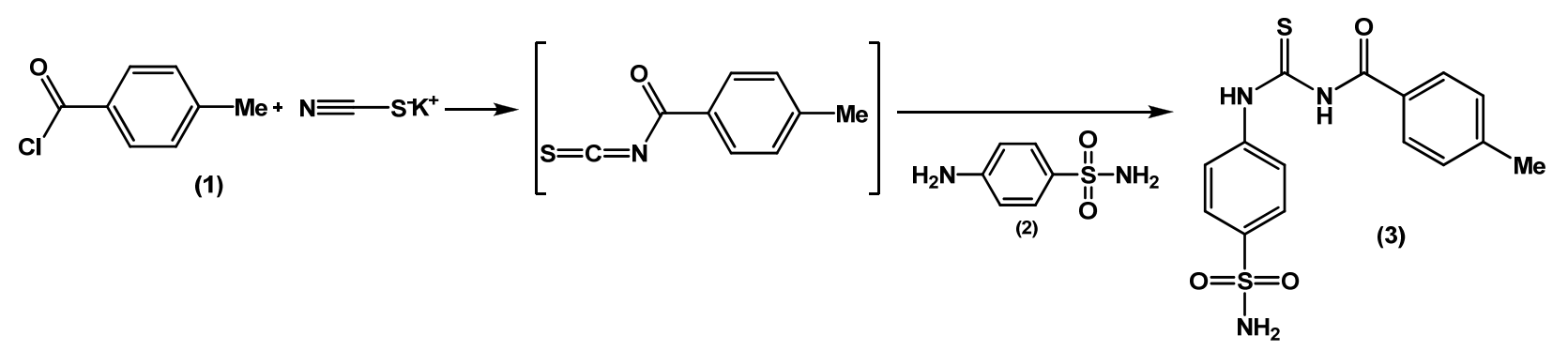

Scheme 1

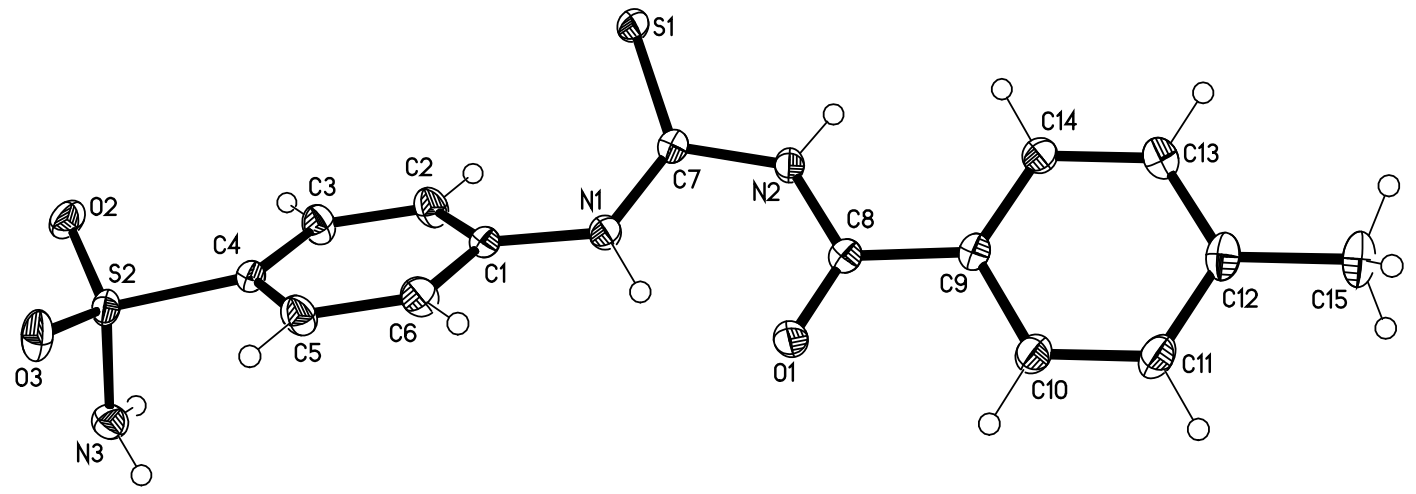

Figure 1. Molecular structure of the title compound with the atom-numbering scheme. Displacement ellipsoids plotted at $50 \%$ probability level.

Table 1. Crystal data and structure refinement for 1-(4-methylbenzoyl)-3(4-aminosulfonylphenyl)thiourea.

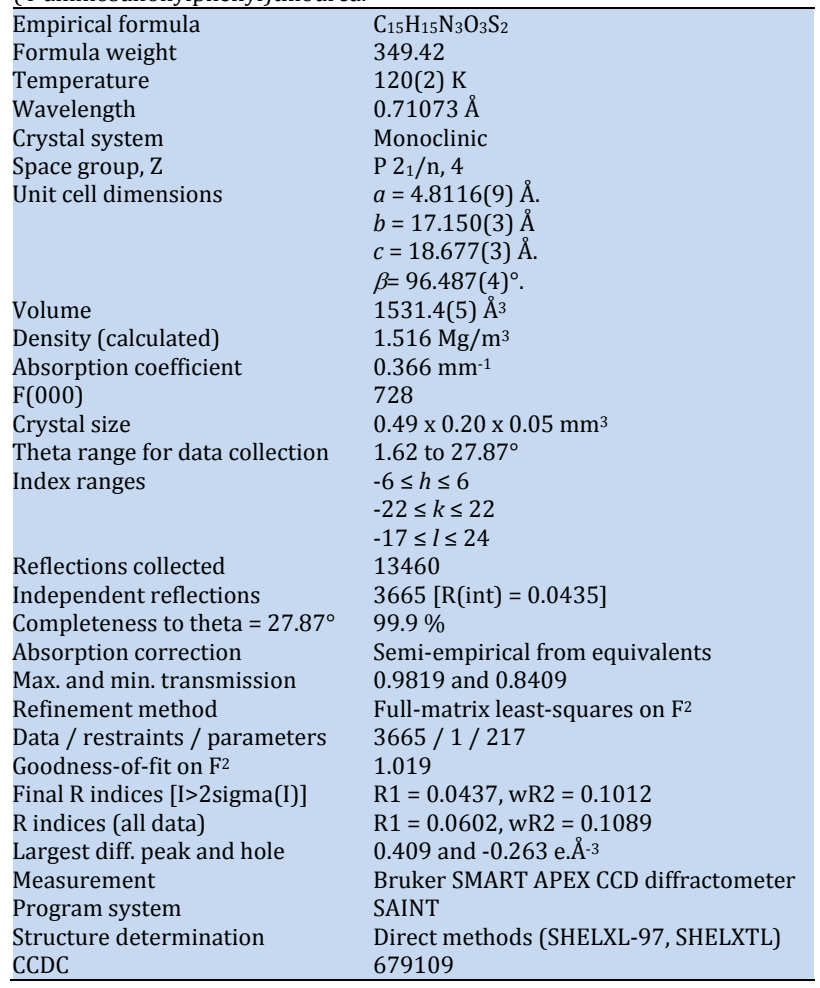

\section{Results and Discussion}

4-Methylbenzoyl chloride (1) was obtained from the corresponding acid according to the standard procedure. It was then treated in a 1:1 molar ratio with potassium thiocyanate in dry acetone to afford the 4-methylbenzoyl isothiocyante intermediate which was not separated. Condensation of the latter with an equimolar quantity of sulfanilamide (2) in anhydrous acetone furnished the 1-(4-methylbenzoyl)-3-(4aminosulfonylphenyl)thiourea (3) in 91\% yield (Scheme 1).

Colorless crystals of 1-(4-methylbenzoyl)-3-(4-amino sulfonylphenyl)thiourea, suitable for X-ray analysis, were obtained by slow evaporation from ethyl acetate/petroleum ether (1:2) solvent mixture. The thiourea was characterized by typical IR stretching vibrations of $\mathrm{N}-\mathrm{H}$ at $3318 \mathrm{~cm}^{-1}, \mathrm{C}=\mathrm{O}$ at $1663 \mathrm{~cm}^{-1}, \mathrm{C}=\mathrm{S}$ at $1263 \mathrm{~cm}^{-1}, \mathrm{C}-\mathrm{N}$ at $1154 \mathrm{~cm}^{-1}$, and $\mathrm{S}=0$ at $1334 \mathrm{~cm}^{-1}$ in addition to the aromatic ring at $1590 \mathrm{~cm}^{-1}$.

In ${ }^{1} \mathrm{H}$ NMR the singlet for the aromatic methyl appeared at $\delta$ 2.43 and the characteristic broad singlets at $\delta 9.19$ and $\delta 12.76$ for the protons of $N_{1}$ and $N_{3}$ respectively. The signals for the aromatic protons were also noted. ${ }^{13} \mathrm{C}$ NMR showed peaks at $\delta$ 23.9 for the aromatic methyl and at $\delta 170.3$ and $\delta 179.4$ for $\mathrm{C}=0$ and $\mathrm{C}=\mathrm{S}$ respectively. Mass spectrum of the compound showed the molecular ion peak at $m / z 304$. The major fragment at $m / z$ 168.9 (50 \%) was derived from the N-McLafferty rearrangement and the base peak at $\mathrm{m} / z 119$ originated from the 4-methylbenzoyl cation.

The molecular structure of the title compound is depicted in Figure 2. Table 1 gives the crystal data and the structure refinement; selected bond lengths and angles as well as hydrogen bonds are presented in Table 2 . The torsion angles C7-N2-C8-01 of $2.3(3)^{\circ}$ and C8-N2-C7-N1 of $-6.1(3)^{\circ}$ reflect the almost planar conformation of the molecule with respect to the thiocarbonyl and carbonyl parts. The two aromatic rings form a dihedral angle of $42.82(8)^{\circ}$ and the associated N2-C8-C9-C10 torsion angle is $9.6(3)^{\circ}$. Bond parameters (Table 1) in general are typical for this type of a compound. Similar geometric parameters are valid for the related molecular structures of 1 (4-Methylbenzoyl)-3-(4-nitro/halogeno-phenyl)thiourea [911]; the most distinct difference is reflected by the dihedral angles between the aryl rings: for the nitro compound [11] it is $28.1(1)^{\circ}$, for the $\mathrm{Br}[12]$ and the $\mathrm{Cl}$ compounds [10] it measures $14.3(1)^{\circ}$ and $30.5(1)^{\circ}$, respectively. Strong intermolecular N(3)- 
$\mathrm{H}$...O(2) hydrogen bonds link molecules to head-to-head dimers that are stacked along [100] (Table 2).

Table 2. Selected geometric parameters $\left(\AA{ }^{\circ}{ }^{\circ}\right)$ for 1-(4-methylbenzoyl)-3-(4aminosulfonylphenyl)thiourea.

\begin{tabular}{ll}
\hline Bond lengths & \\
\hline S1-C7 & $1.656(2)$ \\
C1-N1 & $1.411(3)$ \\
C7-N1 & $1.346(2)$ \\
C7-N2 & $1.394(2)$ \\
C8-N2 & $1.374(2)$ \\
C8-01 & $1.230(2)$ \\
C8-C9 & $1.479(3)$ \\
S2-C4 & $1.7607(19)$ \\
S2-N3 & $1.6172(19)$ \\
H3-H2 & $0.88(3)$ \\
H2....02 & $2.18(3)$ \\
N3....02 & $3.016(3)$ \\
Bond Angles & \\
C1-N1-C7 & \\
N1-C7-N2 & $128.50(17)$ \\
C7-N2-C8 & $114.38(17)$ \\
N2-C8-C9 & $128.47(16)$ \\
N3-H2 ....02 & $117.40(17)$ \\
\hline
\end{tabular}

\section{Acknowledgement}

A.M. gratefully acknowledges a research scholarship from HEC Islamabad under HEC Indigenous PhD Scholarship 5000 Scheme.

\section{Supplementary material}

CCDC-679109 contains the supplementary crystallographic data for this paper. These data can be obtained free of charge via www.ccdc.cam.ac.uk/data_request/cif, or by e-mailing data_request@ccdc.cam.ac.uk, or by contacting The Cambridge Crystallographic Data Centre, 12 Union Road, Cambridge CB21EZ, UK; fax: +44(0)1223-336033.

\section{References}

[1]. Koch, K.R. Coord. Chem. Rev.2001, 216-217, 473-488

[2]. Krishnamurthy, R.; Govindaraghavan, S.; Narayanasamy, J. Pesticide Science 1999, 52, 145-151.

[3]. Sijia, X.; Liping, D.; Shaoyong, C.; Liangbin, J. Chem. J. Internet 2003, 5, 67-70.

[4]. Wang, X-C.; Wang, V.; Quan, Z-J.; Wang, M-G.; Li, Z. J. Chem. Res., 2005, 61, 689-690.

[5]. Saeed, A.; Parvez, M. J. Heterocyl. Chem. 2006, 43, 1027-1030.

[6]. Snieckus, V; Chem. Rev. 1990, 90, 879-933

[7]. Bestmann, H.J.; Kern, F.; Schafer, D.; Witschel, M.C. Angew. Chem. Int. Ed. Engl. 1992 31, 795-796.

[8]. Stokstad, E. L. R.; Jãoekes, T. H. J. Nutr. 1987, 117; 1335-1341.

[9]. Botet, J.; Mateos, L.; Revuelta, J. L; Santos, M. A. Eukaryotic Cell, 2007, 2102-2111.

[10]. Saeed, A.; Flörke, U. Acta Cryst. 2006, E62, o2924- o2924.

[11]. Yusof, M. S. M.; Hamid, M. A.; Ramli, R. N. H. R.; Yamin, B. M. Acta Cryst. 2006, E62, o2131- o2131.

[12]. Saeed, A.; Flörke, U. Acta Cryst. 2006, E62, o5036-o5036. 